\title{
EL CASTIGO FÍSICO: EL CUERPO COMO REPRESENTACIÓN DE LA PERSONA, UN CAPÍTULO EN LA HISTORIA DE LA OCCIDENTALIZACIÓN DE AMÉRICA, SIGLOS XVI-XVIII**
}

Este trabajo se centra en dos procesos paulatinos, no necesariamente consecutivos cronológicamente, pero indispensablemente ligados entre sí: la condena del castigo físico como pena judicial y la privatización de la mortificación del cuerpo, o el paso de la coacción externa a la autocoacción. Ambos tópicos permiten entender la modernidad como proceso de privatización del cuerpo desde los gestos de "ennoblecimiento del cuerpo" y de "compasión por el cuerpo". Se revisan aspectos del debate sobre el castigo físico -como elemento significativo del proceso de occidentalización de América-, desde los discursos en la documentación judicial, en los textos jurídicos referidos a las penas aflictivas en el sistema colonial penal y el debate sobre la mortificación corporal en el ámbito religioso. Teórica y metodológicamente se trabaja desde la historia de las mentalidades y del cuerpo usando las propuestas teóricas de David Le Breton, Mary Douglas, Norbert Elias, René Girard y Serge Gruzinski.

Palabras clave: periodo colonial, historia del cuerpo, historia de las mentalidades, castigos físicos.

This work centres on two gradual processes that in spite of not being chronologically consecutive are necessarily joined: the penalty of the physical punishment like a judicial sentence and the privatization of the mortification of the body, or the step of the external constraint to the auto-constraint. Both topics allow to understand the modernity as process of privatization of the body from the gestures of "ennoblement of the body" and of "pity for the body ". For this purpose, we will check the debates on the physical punishment as significant element of the process of "occidentalización" of America, from the judicial speeches referred to distressing sentences in the colonial penal system and the debate on the corporal mortification in the religious area. The theoretical and methodological line centres on the history of the mentalities and of the body following the offers of David Le Breton, Mary Douglas, Norbert Elias, René Girard and Serge Gruzinski

Key words: colonial age, history of the body, history of the mentalities, physical punishment.

* Universidad de Chile. Investigadora del Centro de Investigaciones Diego Barros Arana de la Biblioteca Nacional. Correo electrónico:alaraya@uchile.cl

** Este trabajo forma parte del proyecto Fondecyt $N^{\circ}$ 1040964: "El epistolario de una monja chilena del siglo XVIII como un indicio del proceso de construcción del individuo moderno en la sociedad colonial chilena". Una primera versión, en forma de ponencia, fue presentada en el II Congreso Internacional de Artes, Ciencias y Humanidades El cuerpo descifrado, octubre 2005, México D.F. 
El lugar del cuerpo en la sociedad occidental contemporánea parece "encarnar" lo privado y constituir el límite de lo público así como el lugar donde inicia la "persona" y su dignidad. Esta exigencia del presente puede analizarse e historiarse por medio de los mecanismos, prácticas y procedimientos que hicieron del cuerpo la representación de la persona ${ }^{1}$. Un gesto esencial en esta historia es defender el cuerpo del castigo físico aplicado por mano propia o ajena. Si bien me centraré en algunos momentos e indicios de dicho proceso, este me interesa en función de la historia de la "occidentalización" y constitución de la sociedad colonial americana puesto que las concepciones y representaciones sobre el cuerpo son parte de las cosmovisiones de una cultura y el soporte profundo de sus manifestaciones ideológicas ${ }^{2}$.

Propongo dos ejes de trabajo. Uno, más comprensible a "nosotros los actuales", que es la lucha por la igualdad de las personas frente al castigo penal fundamentada en que este se aplica según los delitos y no según la "calidad" de los ejecutores. Esta defensa también se puede llamar proceso de "ennoblecimiento" del cuerpo, en tanto se luchó por extender al cuerpo de los plebeyos la dignidad que solo se atribuía al de los nobles, y que reforzaba su calidad de tales en público, porque estaban exentos de castigos aflictivos e infamantes como el azote. El otro eje, en un plano paralelo, trata de la colonización de América en tanto proceso de occidentalización del imaginario, siendo parte central de él la noción de cuerpo y sus representaciones ${ }^{3}$. En la cultura colonial cristiana la privatización del cuerpo puede leerse desde el gesto de "compasión por el cuerpo" que se da en un debate anterior al de los sistemas penales monárquicos, pero que culturalmente se relacionan puesto que el primero -de los siglos XVI y XVII e incluso medievales- trata de la penitencia, es decir, de las penas.

Ennoblecimiento y compasión por el cuerpo son gestos que se hacen visibles en momentos cruciales en la historia de Occidente, identificados con lo que suele llamarse tradicionalmente modernidad. En este sentido, este trabajo permite revisar

\footnotetext{
1 La historia del presente como historia de la privatización del cuerpo, y la de él como representación de la persona, la trabajo desde David Le Breton, Antropología del cuerpo y modernidad, Ediciones Nueva Visión, Buenos Aires, 2002; La sociología del cuerpo, Buenos Aires, Ediciones Nueva Visión, 2002. Aspectos de estas temáticas, para los siglos XVI al XVIII, están recogidos en los desarrollos más recientes de la historia del cuerpo. Ver: Histoire du corps, Vol. 1: De la Renaissance aux Lumières, dirigé par Georges Vigarello, París, Éditions du Seuil, 2005.

2 Mary Douglas, Símbolos naturales. Exploraciones en Cosmología, Madrid, Alianza Editorial, 1970, 89. También ver Marcel Mauss, “Técnicas y movimientos corporales”, en: Marcel Mauss, Sociología y Antropología, Madrid, Editorial Tecnos, 1979, 339-356; Bryan Turner, El cuerpo y la sociedad. Exploraciones en teoría social, México, Fondo de Cultura Económica, 1989; Mark Knapp, La comunicación no verbal. El cuerpo y el entorno, Buenos Aires, Paidós Comunicación, $4^{\text {a }}$ reimpresión 1995; Boltanski, Luc, Les usages sociaux du corps, en: Annales. Économies, sociétés, civilisations, $26^{\circ}$ année, París, Armand Colin, $\mathrm{N}^{\circ}$ 1, 1971, 205-233; Alfredo López Austin, Cuerpo humano e ideología. Las concepciones de los antiguos nahuas, México, Universidad Nacional Autónoma de México, 1980; Jacques Galinier, La mitad del mundo. Cuerpo y cosmos en los rituales otomies, México, Universidad Nacional Autónoma de México, 1990.

3 Tomo el término de Serge Gruzinski y su libro, La colonización de lo imaginario. Sociedades indígenas y occidentalización en el México español. Siglos XVI-XVIII, Fondo de Cultura Económica, México, 1995 (2 $2^{a}$ reimpresión).
} 
los criterios con que a veces se la caracteriza y poner el acento en la modernidad en tanto proceso de privatización más que como cambio en las estructuras productivas o en los modelos económicos, o como un periodo claramente delimitado cronológicamente. De este modo, en cierta literatura económica, sociológica e histórica, sería incompatible hablar de modernidad desde las prácticas religiosas, o en los siglos a los cuales me refiero. Sin embargo, como he planteado desde el inicio, lo moderno y la modernidad se entiende prácticas de privatización a ellas como parte de procesos de control de la violencia.

La discusión sobre el castigo del cuerpo, para ser comprendida, debe considerar lo que se entiende como cuerpo, o sus representaciones. De este modo, los castigos y el cuerpo como receptor de estos, son un tema central dentro del proceso de instalación de los códigos de Occidente en América y debiera abordarse como un programa de investigación futuro que permita dar cuenta de las similitudes y diferencias entre las prácticas penales europeas y las de los pueblos americanos. El lugar del castigo del cuerpo en ellas, así como qué lugares del cuerpo eran objeto de castigo, constituyen caminos riquísimos de conocimiento de los códigos de los Otros, así como los elementos que sirvieron de puente entre unos y otros ${ }^{4}$.

En la cultura cristiano-católica la noción de cuerpo sustenta la de persona, ello significa que la persona se constituye y es reconocida como tal cuando controla su parte sensible y no racional porque el "cuerpo" es entendido como el componente material de lo humano y, en tanto tal, se percibe como un obstáculo para la salvación y perfección del alma. Esta premisa se expresa en ser considerado más humano, más racional o espiritual, cuando se deja de ser semejante a los animales o brutos. Los argumentos que sustentan estos discursos parten del reconocimiento de una dicotomía esencial entre alma y cuerpo en la naturaleza de los hombres, y la asignación al segundo de imágenes ligadas a lo bestial, material, terrenal, mutable y, en tanto tal, corruptible. Las reglas y normas de comportamiento religioso son prácticas de control del cuerpo y, en este sentido y dentro del horizonte americano colonial, funcionaron como mecanismos de interiorización de los fundamentos filosóficos, morales y éticos de una sociedad occidental cristiana. Las prácticas de control del cuerpo forman parte de lo que Norbert Elias ha llamado el proceso de "civilización occidental" o el conjunto de prácticas que permiten conformar un aparato de coacción psíquica que aparece como un rasgo decisivo en el hábito de todo individuo "civilizado" y que se encuentran en "íntima relación con la constitución de institutos de monopolio de la violencia física y con la estabilidad creciente de los órganos centrales [los aparatos burocráticos y de Estado]. Solamente con la constitución de tales institutos monopólicos estables se crea ese aparato formativo que sirve para inculcar

4 He trabajado algunos de estos aspectos en el artículo "Justicia, cuerpo y escritura en la sociedad colonial americana: intersticios de transculturación y aculturación" en Roberto Aedo y otros, Espacios de transculturación en América Latina, CECLA. Facultad de Filosofía y Humanidades Universidad de Chile, 2005, 15-32. 
al individuo desde pequeño la costumbre permanente de dominarse"5. De ese modo, el cristianismo, en el proceso de colonización de América, funcionó como ideología porque permitió sustentar discursos sobre la autoridad y organizar el poder en todos los ámbitos de la existencia social.

El proceso de colonización también fue, entonces, la tensión entre diversos sistemas de monopolio de la violencia. Por un lado, estarían los sistemas judiciales por cuanto el atributo central de las autoridades, en los siglos XVI y XVII, era la aplicación de justicia entendida particularmente como reconocimiento de ofensas y aplicación de castigos. Por otro, las prácticas piadosas como métodos de autocontrol. Pareciera ser, entonces, que para hacer del cuerpo en sí, sinónimo de nosotros mismos, debimos otorgarle dignidad, y al mismo tiempo, compadecernos de él. No obstante, hay que destacar la particularidad de la cultura hispana dentro de occidente puesto que en ella la dignidad es entendida predominantemente como decencia. Por ejemplo, se mezclan los códigos de la civilidad con los criterios que definen la calidad de persona dificultando la concreción de la igualdad social, lo que le dio aún más importancia a las normas y prácticas cristianas de autocontrol. Este sello "distintivo" del individuo civilizado en América colonial, hace que evangelización sea entendida también como "civilidad" o domesticación del bárbaro. Este sello parece ser aún más fuerte en los lugares en que la vida de corte fue un mundo que contaba con solo el deseo de vivir de ese modo, más que las condiciones materiales que lo posibilitaban ${ }^{6}$.

Así, es evidente que fuera de los centros virreinales, la encarnación de lo civilizado debían ser los códigos cristianos de convivencia y relación con uno mismo. En América dicho principio fue fundamental para mantener la relación desigual entre conquistados y conquistadores, y posteriormente, para sostener la desigualdad necesaria a una sociedad de Antiguo Régimen. Hay que insistir que la historia que tratamos de delinear, no es lineal, cada una de estas esferas tiene una historicidad en sí misma y diversos elementos deben relacionarse entre sí para dar un resultado inidentificable temporalmente. Otro punto importante es dar cuenta de los modos en que eso puede instalarse como una realidad propiamente actuante que afecte a la mayor cantidad de sujetos posible. Sin embargo, me permito recordar el inicio de este trabajo: historiar la historia del presente (o de los anhelos aún presentes).

5 Norbert Elias, El proceso de civilización. Investigaciones sociogenéticas y psicogenéticas, México, Fondo de Cultura Económica, segunda edición, reimpresión de 1997, 453. Es importante aclarar que el autor, y por tanto en este trabajo, no se entiende civilización desde la tradición imperialista del siglo XIX e inicios del XX, basada en criterios de progreso evolutivo, sino que como un proceso o relación con la violencia sujeta a cambiantes criterios culturales, razón por lo cual lo ganado puede perderse (en términos de "humanidad"), o simplemente, no ser parte del horizonte de una sociedad en los mismos términos que los nuestros.

6 Ver para el caso de Perú y Chile, comparativamente, el trabajo de Jaime Valenzuela Márquez, Las liturgias del poder. Celebraciones públicas y estrategias persuasivas en Chile colonial (16091709), Santiago, Centro de Investigaciones Diego Barros Arana, serie Sociedad y Cultura, 2001. 


\section{LA JUSTICIA PENAL O EL CUERPO EN LO PÚBLICO: UN DEBATE SOBRE LA PERSONA COMO CIUDADANO}

Las reformas penales dentro del llamado absolutismo del siglo XVIII señalan un cambio en las "ideas" sobre la justicia y los castigos. Tenemos un hito de dicha reflexión en el texto De los delitos y las penas del italiano César Beccaria (1738-1794), aparecido en 1764, traducido en la década de 1770 al español. Los textos de juristas, letrados y tratadistas expresan un punto de saturación social respecto de prácticas que otrora no eran discutibles, así como también son síntesis de debates de larga data en las sociedades en que se generan y de la cual forman parte. El texto de César Beccaria permite afirmar que hay un cambio de percepción frente a la propia condición humana, una incomodidad, en tanto relación con el propio cuerpo, que se debe resolver transformando las relaciones sociales y las bases de la autoridad que a fin de cuentas eran la que definían la condición de los individuos dentro de ella. Cuando hablamos de Antiguo Régimen decimos sistema en el cual las bases de la autoridad se encuentran en Dios y en el Rey como representante de él.

La legitimidad de dicha autoridad está en cuestión en el siglo XVIII y se expresa en el debate sobre la tiranía. El problema era que la "fuerza" se expresaba en la capacidad de castigar la que, frecuentemente, se tornaba abuso. La autoridad legítima aumentaría, decía Beccaria, si más que la fuerza fuera la "dulzura y la humanidad" la que la justificase a ojos de todos7. Para que ello no fuese así, todo ciudadano debía saber los fundamentos de su calidad de reo o de inocente, depositada en los códigos de leyes. También contribuiría a ello la existencia de magistrados en tanto terceros o intermediarios entre el rey y los ciudadanos. La Justicia debía alejarse cada vez más de la persona del rey y sostenerse en un sistema en sí mismo justo, basado en el debido proceso y el imperio de la ley. La monarquía se representaba como un cuerpo unido por medio de un orden jerárquico de relaciones de dependencia. El Rey era la cabeza de un cuerpo conformado por sus súbditos ${ }^{8}$. Por lo tanto, podría decirse que el reconocimiento de los súbditos como ciudadanos, supone reconocerlos como cuerpos indivisibles en sí mismos reconociéndoles los atributos de dignidad, soberanía y autoridad que solo eran privativos del rey y la nobleza. En este sentido, individualizar el cuerpo de los súbditos es extender

7 César Beccaria, De los delitos y las penas, edición facsimilar de la edición príncipe en italiano de 1764, seguida de la traducción de Juan Antonio de las Casas, México, Fondo de Cultura Económica, 2002, 208. En adelante Beccaria.

8 La teoría de los dos cuerpos del Rey, y de la monarquía como cuerpo, tiene diversas expresiones en las sociedades de Antiguo Régimen, así como cambios temporales significativos. No obstante, aunque aquí no se desarrolla, debe tenerse en cuenta dicho campo de representaciones para comprender cómo los súbditos van siendo reconocidos en sí mismos como cuerpos independientes, sin posibilidad de ser divididos (individuo) y soberanos respecto del cuerpo de la monarquía del cual eran solo miembros. Ver: Ernst H. Kantarowicz, Los dos cuerpos del rey. Un estudio de teología política medieval, Madrid, Alianza Editorial, 1985; Mariana Terán Fuentes, "El cuerpo ante el rey", en Caleidoscopio. Revista semestral de Ciencias Sociales y Humanidades, año 7, N 13, enero-junio 2003, 131141; Georges Vigarello, "Le corps du roi", en Histoire du corps, Vol. 1: De la Renaissance aux Lumières, dirigé par Georges Vigarello, París, Éditions du Seuil, 2005, 387-409. 
sobre ellos la dignidad de la persona del rey (autoridad). Esto es lo que he llamado "ennoblecimiento del cuerpo" de los súbditos. Un proceso lento que se relacionará con la formulación de otras teorías sobre el fundamento de la autoridad y el concepto de ciudadanía.

Estos debates van dando otro sentido a las prácticas. Por ejemplo, cuando decimos "lucha por el debido proceso" en el ámbito judicial, estamos diciendo que la escritura de papeles sobre un caso permitió alejar la mano del poderoso del cuerpo de los débiles, percibiéndose un resquebrajamiento de la monarquía como cuerpo e individualizar a los súbditos. En los inicios del XIX, en algunos procesos americanos, ya se expresan reparos respecto a que el castigo sea asociado a Justicia y que el juez fuese, incluso, el ejecutor de las penas. El debate sobre el Juez como ejecutor de la ley y la Justicia, es un paso necesario para que este sea despojado del poder de castigar por su propia mano como había sido el principio que daba coherencia al sistema judicial de la monarquía tradicional. El golpe, fuese azote, palmazo o chicotazo, ahora se califica de abuso de poder y se apela al debido proceso. Por ejemplo, el Protector de Naturales, ante el caso de Nicolás Maipo en Rancagua $^{9}$-que había recibido seis chicotazos por el subdelegado del lugar al ser acusado de robo de un carnero y una oveja-, señalaba que esta acción en un juez era siempre reprensible aunque el delito no fuese leve o por necesidad de corrección porque "el juez no tiene manos para usar de ellas contra persona alguna; sus armas son la pluma, y los papeles"10. Dar de chicotazos fue considerada una operación de "yndecoro e impropia del carácter judicial"11. Esto nos da cuenta de una sensibilidad diferente respecto de los jueces que pasa por lo que Beccaria expresaba como moderación de las pasiones particulares como el furor. El punto es: cuáles son los argumentos que autorizan a ejercer violencia sobre otro.

Todo ello define los fundamentos de la justicia política como diferente, para Becaria, de la justicia natural y la justicia divina. La justicia política, o de los hombres, regulaba los actos de autoridad de hombre a hombre los que, de no ser de absoluta necesidad, eran tiránicos. Así, el derecho a castigar, no fundado en la necesidad, era tiranía ${ }^{12}$. Él se hace portavoz de un cuestionamiento cada vez más sentido respecto de la política de los castigos ejemplares o el escarmiento público. Se preguntaba si aun era necesario: "¿Los alaridos de un infeliz revocan acaso el tiempo, que no vuelve acciones ya consumadas?"13. Si el freno de los delitos era el fin de las penas, para Beccaria no tenía sentido "atormentar y afligir a un ente sensible", es decir, al cuerpo. Las penas debían ser escogidas en función de la proporción, ello impresionaría más eficaz y duraderamente sobre los "ánimos de los hombres, y la

\footnotetext{
9 Corregimiento al sur de Santiago, actualmente capital de la Sexta Región de Chile.

10 Archivo Nacional de Chile, Capitanía General, vol. 530, fojas 68-73v, cita foj. 73. Santiago, 1809.

11 Ver más ejemplos en Alejandra Araya, "Justicia, cuerpo y escritura en la sociedad colonial americana: intersticios de transculturación y aculturación”, en Roberto Aedo y otros (editores), Espacios de transculturación en América Latina, Santiago, Centro de Estudios Culturales Latinoamericanos, Santiago, Facultad de Filosofía y Humanidades, Universidad de Chile, 2005, 15-32.

12 Ibidem, 216

13 Beccaria [7], 238
} 
menos dolorosa sobre el cuerpo del reo". Las penas corporales debían ser aplicadas solo en los delitos contra las personas, mas no contra los de los bienes o hacienda puesto que las leyes debían resguardar que en toda situación los hombres fuesen reputados como personas y no como cosas. La calidad de persona, por tanto, tendría directa relación con hacer del cuerpo el lugar de la persona castigándolo solo cuando dañase a un objeto proporcional a él: el cuerpo de otra persona.

$\mathrm{Su}$ razonamiento es pragmático, deriva de constatar a quién se trataba como persona en la práctica según qué tipos de castigos se les aplicaba. Dicha categoría era válida solo para los nobles porque ellos no eran castigados con penas aflictivas o corporales, y se aplicaban sin discusión a los plebeyos. Se preguntaba si era necesaria esa distinción y concluye que «aunque sea verdad que la desigualdad es inevitable o útil en la sociedad lo sea también que debe consistir en las clases que en los individuos... limitareme solo a las penas con que se debe castigar esta clase, afirmando ser las mismas para el primero que para el último ciudadano" 14 .

El azote y otras penas corporales en público, así como la tortura, eran irracionales -por ello injustas- porque no podían formar parte de un sistema de equivalencias como los pagos pecuniarios, los destierros y las confiscaciones. Un sistema de castigos basado en la sensibilidad del cuerpo tenía el límite del propio objeto, la muerte del mismo, limitando a su vez la posibilidad de escarmiento puesto que "un espectáculo muy atroz para la humanidad podrá ser un furor pasajero, pero nunca un sistema constante, cual deben ser las leyes..."15. Concluirá que es mejor evitar los delitos que castigarlos. Sería la "dulzura de las penas", no la crueldad, la que frenaría los delitos. Dicha dulzura era para Beccaria infalibilidad de la pena, se temería por certidumbre del castigo y no por el dolor.

Al comparar estos planteamientos con el debate que se dio en la sociedad hispana, destaca que los elementos cuestionados por Beccaria por su irracionalidad, como asimilar la justicia natural y la divina a la política, o un sistema de castigos que se basase en la calidad de las personas por sobre la calidad de delito o el honor, son definitorios de dicha cultura. El texto de Manuel de Lardizábal Uribe jurista oaxaqueño, titulado Discurso sobre las penas, publicado en 1782 nos permite ilustrar lo dicho ${ }^{16}$. Escrito por encargo de Carlos III dentro de un proyecto de reforma procesal penal, tiene como interlocutor el debate que generó el texto de Beccaria. Este obligó a reconocer a la monarquía que era necesario revisar el sistema de castigos, pero la opción española fue eliminar los abusos para seguir siendo un buen gobierno, no la reforma de los fundamentos del sistema. Su tratado inicia con una defensa de la teoría de derecho divino. Siendo un tratado por encargo del propio Rey, aborda la discusión sobre las penas dentro de la tradición teórica del buen gobierno, cuya eficacia se medía en la paz social la que era posible solo si el rey era justo.

14 Ibidem, 261.

15 Ibidem [7], 273

16 Manuel de Lardizábal y Uribe, Discurso sobre las penas, México, edición facsimilar [Madrid, 1782], Fondo de Cultura Económica, 1962. En adelante Lardizábal. 
Es importante destacar la razón por la cual no era posible aceptar en España, y sus reinos, el contrato social como fundamento de un buen gobierno. El contrato social suponía, para Lardizábal, consentir en una soberanía repartida en todos los súbditos y delegada en un rey que por potestad de ellos tenía autoridad, por tanto, antes de ese pacto era un igual. Si esto se modificaba, entonces, dónde quedaba el principio fundante de toda autoridad que era justamente la "superioridad”: “...¿Y cómo se podría salvar esta superioridad, si el inferior pudiese restringir y moderar las facultades del superior?"17. La desigualdad no solo era necesaria, sino que parte del orden creado por Dios: superiores e inferiores. En esta lógica, la pena capital era necesaria porque permitía cumplir el objetivo de mantener la paz evitando sediciones y alborotos. Igual objetivo cumplían, por tanto, todas las penas aflictivas o corporales. Si bien comparte con Beccaria que la pena capital era un espectáculo momentáneo y eso podía debilitar el argumento de su necesidad, era más eficaz que la privación de libertad, porque la vida era el mayor bien ${ }^{18}$. También era una medida racional de gobierno puesto que en una "monarquía dilatada" como la española, el espectáculo de la muerte era un instrumento necesario como representación del poder del monarca en tierras lejanas, es decir, una demostración de su presencia. Sí debían buscarse modos menos crueles que el garrote, la horca y arcabuceo para ejecutar la pena de muerte, porque el fin de las penas no era atormentar, sino que corregir.

Que el tratado de Lardizábal se dedique casi exclusivamente a las penas corporales o aflictivas definidas como "aquellas que afligen el cuerpo, ya causando dolor, ya privando de ciertas comodidades, ya causando ciertas incomodidades" da cuenta de la importancia de la relación entre cuerpo e ideología en la monarquía hispano católica. Entre estas penas, a juicio de Lardizábal, las más graves eran las que mutilaban miembros. Las penas "inhumanas" debían conmutarse por galeras o vergüenza pública. Ellas eran desollar la frente, imprimir hierros ardiendo en la cara u otra parte del cuerpo, sacar los ojos, cortar o clavar la lengua, cortar las orejas, arrancar los dientes, clavar la mano ${ }^{19}$. Todas aparecen en la casuística

17 Lardizábal [16], 171. Lardizábal, oriundo de Tlaxcala, Nueva España, pasó a España en 1761 luego de estudiar en el Colegio de San Ildefonso en México. Llegó a ser doctor de la Escuela de Letrados y Ministros de la Real Cancillería, y formó parte de los encargados de formar y extender el Nuevo Código Criminal ("Carolino") en 1770. Se le llamó "el abogado americano".

18 En este punto es interesante lo planteado por Michel Foucault respecto del traslado de las coacciones públicas, el espectáculo del escarmiento, a la mortificación de la propia conciencia en la prisión y el sistema del panóptico. Ver del autor, Vigilar y castigar. Nacimiento de la prisión, México, vigésima tercera edición en español, 1995). Él ve en esto una tecnología del ejercicio del poder más refinada y más certera coincidiendo en ciertos aspectos con Norbert Elías respecto de la mayor efectividad de las coacciones psíquicas, que Foucault denomina tecnologías del Yo. Ver del autor, Tecnologías del yo, Barcelona, Paidós. I.C.E-U.A.B., 1996. Sin embargo, revisando la discusión de los escritos de época, el argumento de la "necesidad" de aplicar dolor en el cuerpo pasa al de las restricciones del movimiento del cuerpo diciendo con ello que para los hombres es cada vez más valiosa su libertad física, que su propia vida corporal. Y esto no tiene que ver necesariamente con los procesos de institucionalización del monopolio de la violencia. Como señalaré más adelante, una lectura más profunda indica que el debate no se da solo a nivel político filosófico sobre el poder, sino también sobre la necesidad del dolor físico y cómo la protección del cuerpo de él será sinónimo de dignidad y forma efectiva de exigir el derecho a la calidad de persona y ser humano.

19 Lardizábal [16], 190-191. 
americana, sobre todo aplicada a esclavos negros y a indígenas, precisamente los protagonistas de la discusión sobre la cosificación y la noción de persona.

Otra particularidad del caso español, y del americano, es el lugar del azote y las diversas formas de golpear un hombre a otro hombre por propia mano. Era la pena que "marcaba", literal y carnalmente, la diferencia entre hombres superiores e inferiores. Dice Lardizábal: "muy usada entre nosotros para castigar ciertos delitos en la gente del pueblo inferior" 20 .

Los castigos ya tenían un dictamen respecto de quienes los merecían porque infame era el "notado de ruin fama; y particularmente son infames aquellos a los cuales el derecho señala por tales...". Es decir, la ley y la justicia permitían sancionar la diferencia entre hombres con más posibilidades de cometer delitos, por tener culpa o mancha, puesto que infamia es "la mácula, la nota torpe y ruin, la mala fama y reputación" 21 . Los hombres ruines cometían delitos, si los cometían merecían azotes, y nuevamente quedaban infamados. La ruindad caracterizaba a lo inferior, merecían por tanto un castigo acorde con esa vileza. Ruin es ser "bajo y despreciable", "vale malo", lo vil es la cosa "desmedrada, pequeña y humilde" y por ello también se aplicaba a los hombres de "pocas obligaciones, malas costumbres y procedimientos. Aplícase a las mismas costumbres o cosas malas", dice un diccionario del XVIII que relaciona este término con la "bilis" al ponerlo como sinónimo de ruin y malo ${ }^{22}$. El diccionario de Covarrubias, del XVII solo decía que ruin era un "hombre de mal trato, o cosa que no es buena" 23 , pero claramente en el siglo posterior se ha asociado esto a la gente "inferior" como dice Lardizábal, es decir, lo "bajo" es vil.

Para explicar mejor la connotación social de este desplazamiento, revisemos la definición de vil del XVII: "del nombre latino VILIS, valer hombre bajo, de ruin casta y de poca estima, y aunque se escribe con una 1, puede traer origen del nombre villa, que vale aldea, y que sea vil lo mismo que villano; y dice más la bajeza de su persona y de su condición y trato, porque deste nombre deducen el de biliaco o bellaco; sin embargo que lo más cierto sea de belial" ${ }^{24}$. Así, el hombre vil lo es por estar abajo y lo está por el peso, podría decirse, de sus manchas como explica unas de las definiciones que señalaba al infame como el poseedor de una mácula. Ya está caído o, después de la pena aflictiva, llevará la marca indeleble de esa caída. El azote daña el cuerpo en un sentido profundo porque el golpe puede hacer caer y eso es lo a lo que remite el término mácula de la cual es sinónimo infamia. Caer, es hacerse inferior. Y el que cae, es débil, por tanto culpable. Mácula vendría del hebreo macar o "la fruta que, cayendo en tierra, ha recibido

20 Ibidem, 192.

21 Sebastián de Orozco Covarrubias, Tesoro de la lengua castellana o española, Madrid Editorial Castalia, edición de Felipe C.R. Maldonado, 1995 [original de 1611], 666. En adelante Covarrubias .

22 Diccionario de la lengua castellana, en que se explica el verdadero sentido de las voces, su naturaleza y calidad, compuesto por la Real Academia Española, tomo V, Madrid, Imprenta de la Real Academia Española, 1737, 653. Primera edición del diccionario de la Real Academia, conocido posteriormente como Diccionario de Autoridades.

23 Ibidem, 872

24 Ibidem, 966. 
golpe, y por aquella parte se va pudriendo, como membrillo macado... vale herida o golpe" 25 . Eso relaciona el azote, y las penas corporales, con la concepción cristiana del cuerpo como portador e incluso responsable de la mancha o pecado original. De otro lado, solo el castigo del cuerpo puede redimirlo, purificándolo a golpes y derramando su sangre. Al ser el cuerpo, como señala Mary Douglas, el mayor símbolo natural que posee toda sociedad siempre soporta la teoría social explicativa del orden imperante puesto que es un microcosmos y medida de todas las cosas, a partir de él se define la relación primordial entre lo alto y lo bajo ${ }^{26}$.

Los azotes eran necesarios, pero según lo expresado por Lardizábal, al parecer en el siglo XVIII se estaban aplicando indiscriminadamente y ello podía amenazar el sosiego público porque el azote, al infamar, sería fuente de resentimientos y agravios, contradiciendo el fin de la aplicación de justicia que era la paz ${ }^{27}$. Los argumentos que da para considerar la utilidad o no de los azotes, no provienen de principios morales, sino de una reflexión política -la pacífica relación con los inferiores o los súbditos infamados podía resquebrajarse- y, por otro, un asunto de idiosincrasia: no era honorable. Si los azotes eran viles y hacía tal a quien los recibía, al perder su vergüenza o su honor, perdían el freno para cometer otros delitos. Debía respetarse ese bien, que casi era sinónimo de vida: "Por regla general, en una nación honrada y pundonorosa, qual es la Española [sic], toda pena de vergüenza usada con prudencia, y haciendo distinción en el modo de imponerla, según la distinción de clases y personas, puede producir muy saludables efectos" 28 .

En el mundo español, el pudor y la decencia son valores sociales e ideológicos al punto que regirse por ellos es lo que permite ir reformando el sistema penal, por ejemplo, dejar de sacar a la vergüenza pública a las mujeres desnudas de "medio cuerpo arriba con los pechos descubiertos, lo que ciertamente ofende la modestia"29. Es justo, dice Lardizábal, guardar "una exacta y justa proporción en las penas" revisando la crueldad de las mismas según los criterios del honor ajustado a las calidades de las personas, era poco decente excederse. Se debe resguardar una sociedad de desiguales en calidades, pero sin excesos, sin faltar a la decencia. Así puede entenderse que la exposición pública de la falta de honor o de los excesos permita en América a esclavos y sirvientes defenderse de los golpes ya fuese ante la Inquisición o ante los jueces civiles.

Si sobre el pueblo inferior se aplicaba la mayor parte de las penas corporales era porque protagonizaban gran parte de los delitos, aunque esta declaración proviene más bien de un discurso sin salida o sin otra salida posible: lo bajo lo es por infame, manchado, entonces, solo lo bajo, los plebeyos, tienen tendencia al delito. Por ello, señala Lardizábal, para frenarlos no bastaba con revisar el sistema penal

25 Ibidem, 725.

26 Ver Mary Douglas [2], 89. En el capítulo dos, sostiene la teoría de los dos cuerpos: el natural y el social. Uno refuerza las categorías del otro, produciéndose una relación simbiótica entre la teoría social y las representaciones del cuerpo natural.

27 Lardizábal [16], 192-193.

28 Ibidem, 195.

29 Lardizábal [16], 196. 
sino también procurar dar por todos los medios posibles "una buena educación al pueblo, para evitar la ociosidad y la mendicidad, que son las fuentes más fecundas de delitos y desórdenes" 30 . La ociosidad y la mendicidad permiten decir que las teorías sobre la criminalidad se entienden como teorías políticas puesto que el ocio será sinónimo de caos, peligro y desorden. La decencia, por ejemplo, también se leerá como presencia de trabajo y eso será un requisito para reconocer en otro la calidad de persona y, posteriormente, de ciudadano, como puede revisarse en la persecución a los vagos ya sea por medio del procesamiento de ellos o la legislación para ellos en América ${ }^{31}$. Los vagos se entendían como la "polilla de las costumbres y de la república", por eso las leyes contra ellos eran consideradas "justísimas, y contendrán en gran parte el mal"32.

La estrecha relación entre Iglesia y Estado hace que las discusiones ilustradas a la "española y americana", un proceso entre dos aguas: por un lado, la historia de la relación con el cuerpo en el cristianismo que se erige como criterio diferenciador entre conquistadores y conquistados y, por otra, el uso de los códigos de la decencia como fundamento de una teoría social en que inferiores y superiores lo son por las relaciones de control que son capaces de establecer con el propio cuerpo.

La mácula, que está presente en la cuestión del honor, es también el centro del sistema penitencial católico y también en la institución que debía resguardar la pureza de la fe: la Inquisición. Institución que llegó a convertirse en sinónimo de tortura en el imaginario occidental ${ }^{33}$. Este es otro de los temas problemáticos en el debate sobre los delitos y las penas. Para Beccaria, la condena a la tortura o tormento, está dada por el secreto en que ella se hace, esto es, que escapa al dominio de lo público en que debían fundarse las leyes y el pacto social y porque se hacía como parte del proceso y no como resultado del mismo. No tenía sentido que un hombre fuese al mismo tiempo acusador y acusado al confesar por tortura, es decir "que el dolor sea el crisol de la verdad, como si el juicio de ella residiese en los músculos y fibras de un miserable. Este es el medio seguro de absolver a los robustos malvados y condenar a los flacos inocentes" 34 . El fin de las penas no era

30 Lardizábal [16], 206.

31 Veáse Alejandra Araya Espinoza, Ociosos, vagabundos y malentretenidos en Chile colonial. Santiago de Chile: DIBAM. LOM. Centro de Investigaciones Diego Barros Arana, 1999; "Guerra, intolerancia a la ociosidad y resistencia: los discursos ocultos tras la vagancia. Ciudad de México 1821-1860": Boletín Americanista, Universidad de Barcelona, Año LII, No 52, 2002, 23-56; "De los límites de la modernidad a la subversión de la obscenidad: vagos, mendigos y populacho en México, 1821-1871", en Romana Falcón (coord.), Culturas de pobreza y resistencia. Estudios de marginados, proscritos y descontentos, El Colegio de México/Universidad Autónoma de Querétaro, México,2005, 45-72.

32 Lardizábal [16], 207-209.

33 Ver Solange Alberro, Inquisición y sociedad en México, 1571-1700, México, Fondo de Cultura Económica, 2000 y Claudia Arancibia, Carolina González y José Tomás Cornejo, "Veis aquí el Potro del tormento? ¡Decid la verdad! Tortura judicial en la Real Audiencia de Santiago de Chile, en Revista de Historia Social y de las Mentalidades, No 4, 2000, Universidad de Santiago de Chile, 131150 y de los mismos autores, Pena de muerte en Chile colonial, Santiago, RIL Editores. Centro de Investigaciones Diego Barros Arana, 2003.

34 Beccaria [7], 247 
el terror de los otros hombres, como ridículo era pensar que la tortura era el único medio para purgar la infamia. ¿Debía un hombre confirmar su infamia, para liberarse de ella, por medio de su "deposición con la dislocación de sus huesos"? Este abuso, dice Beccaria, "no se debería tolerar en el siglo XVIII. Se cree que el dolor, siendo una sensación, purgue la infamia, que es una mera relación moral. Se dirá acaso que el dolor es un crisol; ¿pero la infamia es acaso un cuerpo mixto puro?". Es una ley ridícula, un uso tomado, al parecer dice Beccaria de la influencia de las ideas religiosas y espirituales que "tienen tanta influencia sobre los pensamientos de los hombres, sobre las naciones y sobre los siglos. Un dogma infalible asegura que las manchas contraídas por la agilidad humana, y que no ha merecido la ira eterna del Supremo Ser, deben purgarse por un fuego incomprensible; pues siendo la infamia una mancha civil, así como el dolor y el fuego quitan las manchas espirituales, ¿por qué los dolores del tormento no quitarán la mancha civil que es la infamia?" Esta influencia de lo religioso en lo civil explicaría que en algunos tribunales se exigiese la confesión como algo esencial para la condenación, porque en el "misterioso tribunal de la penitencia" la confesión de los pecados es esencial para el sacramento ${ }^{35}$.

Esto debe considerarse para el caso americano, puesto que hay diversidad en la forma de realizar los procesos y en particular en la inclusión de la confesión como parte del mismo así como sobre la tortura, e incluso en la existencia o no de un proceso judicial en forma escrita y regulada. Lardizábal concuerda con Beccaria sobre lo innecesario de la tortura citando textualmente al italiano. Y agrega un argumento "hispano", la honra como valor de la palabra dada: no se podía dar crédito a la proferida en momentos de desesperación por los agudos dolores del tormento. Su condena a la tortura se sustenta en mostrar que ella no estaba autorizada en las leyes como muchos creían, que era nada más un uso. Impugnar la tortura, si ella no estaba avalada por la ley de Dios ni del monarca, no era faltar el respeto a la autoridad como algunos de sus defensores argumentaban. Lardizábal les recordaba que muchas prácticas habían sido condenadas por la propia Iglesia como superstición, por ejemplo, los llamados juicios de Dios "por tanto, la ley debe adecuarse al tiempo y circunstancias de un "siglo" 36 . No obstante, muchos opinaban que era necesaria para poner "freno" a los delitos, averiguarlos y castigarlos, pero si eso fuese así, dice Lardizábal, por qué era solo para algunas clases de personas: “¿No tiene la sociedad igual derecho de ser liberada de los perjuicios del noble, que del plebeyo? Y si los delitos de los nobles pueden averiguarse y castigarse sin el tormento, ¿por qué no podrán averiguarse también los de los demás hombres? Dicho principio de excepción de los nobles se habría tomado de los romanos que aplicaban la tortura solo a los esclavos, "a quienes tenían quitado todo derecho de personalidad, reputándolos como muebles o como bestias; pero nunca en los ciudadanos" ${ }^{37}$. Así, en España

\footnotetext{
35 Ibidem, 248.

36 Lardizábal [16], ver 267 y siguientes.

37 Ibidem, 282-283.
} 
se solía aplicar el tormento a la servidumbre y a los plebeyos a quienes, por tanto, no se les daba el atributo de personas ${ }^{38}$.

Esto incomoda a Lardizábal pero no tomó el camino que podía traerle más problemas (impugnar los fundamentos de dichas diferencias), sino que apeló a la piedad y bondad del Rey: "Yo le diré, que por lo mismo debemos esperar, que el piadoso y benéfico Carlos III, convencido por las reflexiones y experiencia de sus Magistrados, a imitación del Monarca Francés, abolirla también en su Monarquía el tormento, y querrá señalar su dichoso Reynado con este nuevo acto de humanidad" 39 .

He aquí entonces, que no obstante que en el siglo XVIII se concretan y expresan claramente otras ideas sobre la justicia, la dignidad de las personas y las relaciones entre los hombres, ellas tienen en el centro una discusión sobre la noción de persona en relación con el dolor infligido al cuerpo. Podría decirse que las ideas consideradas propias de la modernidad sobre la sociedad y los derechos de las personas se sustentan en una suerte de gesto compasivo hacia él. ¿Cómo y por qué se llega a decir que peor que la muerte es el dolor? ¿Qué tipo de prácticas son necesarias para producir una nueva relación con el cuerpo que no sea simplemente decir que otras ideas comienzan a regir las explicaciones del mundo?, ¿a qué nuevas sensibilidades profundas responden esas sistematizaciones del pensamiento?

\section{PENA Y PENITENCIAS: LA COMPASIÓN POR EL CUERPO EN PRIVADO}

La discusión sobre la ley de Dios y la ley de los hombres nacida de un pacto social supone una definición precisa de los delitos diferenciándolos de los pecados, es decir, lo que es del César al César y lo que es de Dios a Dios. Así, Beccaria señala que entiende por justicia solo la política, y no la "suerte de justicia que dimana de Dios, y que tiene inmediatas relaciones con las penas y recompensas eternas" 40 . Pero en América, la conquista se hace en conjunción de ambas esferas. Por tanto, en nuestro caso es difícil separar la noción de pecado de la de delito porque el primero le da sustento filosófico y moral tanto a las nociones de justicia como a los sistemas penales que, entonces, tienen mayor relación con una noción

\footnotetext{
38 Tanto los azotes como la pena de muerte eran aplicados efectivamente a los plebeyos, los que no se consideraban tales, y podían probarlo, se liberaban de ella por origen y "calidad" o por conmutación de la pena en pago pecuniario, por ejemplo, en el caso de los comerciantes. El trabajo de Sebastián Rivera sobre los verdugos, también muestra que la aplicación de los castigos era un tema complicado incluso por la dificultad para conseguir al ejecutar de la pena. Ser verdugo era un oficio infame, por tanto infame el elegido, muchas veces redimido de sus culpas o delitos por el cargo y protegida su identidad por una capucha. En el caso chileno, hasta 1778 fueron esclavos e indios, es decir, gente en sí misma considerada inferior y cosificada al perder libertad, algunos de ellos ya anunciaban la práctica posterior de salvar su vida o conmutar la pena de muerte, merecida por su larga carrera de delitos, convirtiéndose en verdugos o "esclavos del Rey". Ver especialmente el cuadro de los verdugos del siglo XVIII en página 10, en Sebastián Rivera, Elite y Plebe en Chile colonial (17501800). El verdugo: entre la rebeldía y el disciplinamiento, Tesis para optar al grado de Licenciado en Historia, Santiago, Universidad de Chile, 2005.

39 Lardizábal [16], 288.

40 Beccaria [7], 218.
} 
sacrificial del castigo ${ }^{41}$. Esto es lo que ejemplificamos con la relación entre castigo, infamia y mácula reseñada en el apartado anterior. Problema evidente para los tratadistas comentados.

Las discusiones sobre el sacramento de la penitencia, de mayor data que las que refieren a la proporcionalidad de las penas, permiten explicitar estas complejas relaciones que pasan a ser una suerte de "interferencias" a las reformas dieciochescas en sociedades en que el cristianismo es más que profesión de fe, distintivo cultural y herramienta de dominio. ¿Qué pasa entonces con el proceso de ennoblecimiento del cuerpo, desde el campo jurídico político, en sociedades cristianas o que deben ser cristianizadas como la sociedad colonial? En ellas, la protección del cuerpo, como vimos en el texto de Lardizábal, se sustenta en el entramado cultural de la monarquía cristiana: la piedad del Rey. Ahora bien, al tratar sobre las penas y las penitencias, dentro de una cosmovisión cristiana, decimos ¿quién es el culpable o el criminal responsable de la caída y la pérdida de la justicia de Dios? La parte material y sensible de lo humano: su cuerpo.

Lo que permite transformar la visión que se construyó de él como culpable y criminal, es sentir compasión de su naturaleza. Compadecerse es tener misericordia del afligido y menesteroso ${ }^{42}$. El cuerpo, por tanto, debe comenzar a ser apreciado como afligido, como no digno de ser derribado "por el suelo" o "traer debajo de los pies" -si seguimos las etimologías- razón por la cual comúnmente "afligir se toma por oprimir, desconsolar, atormentar, angustiar" 43 . El cuerpo debe pasar a ser un necesitado, este es el sentido de menesteroso, un "pobrecito" cuerpo, que evidentemente puede llegar a ser "pobrecito yo". Allí se está a un paso de cuestionar por qué razón nuestro cuerpo debe sufrir para pagar las culpas. Cuál será entonces la relación entre la pena y la culpa. La primera se da en razón de la segunda. Pena, en un sentido más amplio que el jurídico es "cuidado y congoja"44. Por lo tanto, la

41 Tal como señala René Girard, aún estamos lejos de comprender bien por qué la regulación de la violencia supone más violencia. Los comportamientos religiosos y morales, entre los que se cuenta la justicia y el derecho, apuntan a la no violencia de manera inmediata en la vida cotidiana, y de forma mediata, en la vida ritual, como intermediario paradójico de la violencia. De este modo, si en el contexto que nos ocupa la justicia está ligada a un monarca cristiano cuya misión en América era traer ese orden, el proceso por el cual el sistema judicial batalla por la independencia y racionalidad de los castigos, se da dentro del orden de los sacrificios es decir en el "espíritu de la pietas" como señaló explícitamente el texto de Lardizábal y esto, a juicio de Girard, es característico de la vida religiosa. Razonamiento que comparte Beccaria y que le incomoda profundamente por ello hace la distinción entre justicia política y justicia divina. Esa separación imposible en el caso español hace que el paso entre una justicia preventiva y otra curativa, en términos de Girard, sean más complejas y lentas. Ambos tipos de justicia tiene por fin protegerse de la venganza interminable que supone la violencia. Los medios preventivos desvían el espíritu de venganza por medios sacrificiales como el escarmiento público tal como se aplican los castigos corporales en el Antiguo Régimen. Los sistemas propiamente judiciales, para este autor, serían los que irían paulatinamente imponiéndose con el debate ilustrado (considerados por eso más "civilizados" o "modernos", asunto discutible) y luego el del derecho positivo por cuanto buscan mecanismos "racionales" de compensación que no sea la aplicación de más violencia o al menos que esta tenga fundamentos claros y no arbitrarios. Ese es el meollo de la discusión revisada respecto de la tiranía y la necesidad de aplicar dolor para purgar un delito. Sigo a René Girard en La violencia y lo sagrado, Barcelona, Anagrama, 1995, en particular las páginas 28 y 29.

42 Covarrubias [21], 338.

43 Ibidem, 22-23.

44 Ibidem, 812. 
pena es un sufrimiento que se merece en razón de tener culpa, sinónimo de causa, mérito y crimen.

En culturas en que la justicia se entiende como "purgación" y el sistema social se sustenta en el concepto de "pureza", el cuerpo humano se torna el objeto del castigo porque se lo asocia al pecado o mancha ${ }^{45}$. Pecado podría derivar, etimológicamente, de peca que es tanto mancha como lástima: "la señal o mancha que sale sobre el cuero, especialmente en la cara. En latín se llaman máculas, pero sospecho que el vocablo peca (señala el autor) es italiano y vale cosa que causa lástima, conforme a una frasis [sic] suya e un peccato, es lástima"46. Así, en el cristianismo católico el cuerpo es considerado el culpable de la caída por su naturaleza material, inestable y corruptible por eso se le llama en los textos religiosos el "enemigo doméstico". Es esencial para un cristiano reconocer esa debilidad natural, su culpabilidad de origen, la mácula. Del "odio santo de sí mismo" nace el espíritu de mortificación y penitencia, y este se genera de concebir que este "nuestro cuerpo es el mayor contrario y enemigo que tenemos... Enemigo mortal, el mayor traidor que nunca se vio, que anda buscando la muerte y muerte eterna, a quien le da de comer y todo lo que ha menester; que por haber él un poco de placer, no tiene en nada dar en ojos a Dios y echar el ánima en el infierno para siempre jamás" 47 . Muchas de estas prácticas tendían a la negación de sí mismos en tanto la principal virtud que debía cultivarse era la humildad la que se conseguía ejercitando la humillación de la propia naturaleza y la voluntad. Esa naturaleza estaba contenida en su calidad de seres de compostura mixta, es decir manchados, al ser espíritu y materia. En el fondo de este debate, se encuentra la discusión teológica respecto de las pasiones como atributos del cuerpo carnal y su "desorden" como causa y a su vez consecuencia del pecado original.

La caída, o pérdida de la justicia de Dios, podía recuperarse con trabajos y penitencias. Este tema fue el protagonista de muchos debates en el Concilio de Trento (1545-1563) relativos a la penitencia o mortificación corporal que, otrora públicas, serían un acto privado resultado del también privado sacramento de la penitencia en la forma de la confesión ${ }^{48}$. Este debate continuará en los siglos posteriores. La mortificación tendrá dos lecturas: la aflicción del cuerpo y el disciplinamiento de él por medio de la propia voluntad, venciendo los sentidos y movimientos de la naturaleza carnal. Había que volver al estado original, armónico, por medio de la sujeción, dominio y subordinación de lo inferior a lo superior a lo que ayudaba la disciplina monástica de las reglas y constituciones, pero que el religioso o piadoso cristiano, debía reforzar y conseguir por medio de las mortificaciones internas y externas puesto que su principal enemigo era el propio cuerpo, cárcel del alma:

45 Ver Alejandra Araya Espinoza, "La pureza y la carne: el cuerpo de las mujeres en el imaginario político de la sociedad colonial", en Revista de Historia Social y de las Mentalidades, Vol. 1/2, 2004, 67-90.

46 Covarrubias [21], 809.

47 Alonso Rodríguez, S.J., Ejercicio de perfección y virtudes cristianas, dividido en tres partes, dirigido a los religiosos de la misma Compañía, Madrid, Editorial Apostolado de la Prensa, S.A., 1954, Parte segunda, tratado primero de la mortificación, 621.

48 Ver Jean Delumeau, La confesión y el perdón, Madrid, Alianza Universidad, 1992. 
antes del pecado, en aquel dichoso estado de inocencia y justicia original en que Dios crió al hombre, esta porción inferior estaba perfectamente sujeta a la superior, el apetito a la razón, como cosa menos noble a la más noble, y como natural siervo a su señor...; no crió Dios al hombre desordenado, como ahora estamos, entonces, sin ninguna dificultad ni contradicción, antes con mucha facilidad y suavidad obedecía el apetito a la razón y se iba el hombre a amar a su Criador... No fuéramos entonces tentados de ira, ni de envidia, ni de gula, ni de lujuria, ni de otro mal deseo, si no es que nosotros por nuestra voluntad le quisiéremos tener. Empero por el pecado, como la razón se rebeló contra Dios, rebelóse también el apetito sensitivo contra la razón... Contra toda vuestra voluntad, aunque os pese, se levantan en vuestro apetito sensitivo movimientos y aficiones contrarias.

Y más, si el hombre no pecara, el cuerpo estuviera dispuesto para cualquier obra que el alma quisiera ejercitar, que no sintiera en él ningún impedimento. Pero ahora (Sap., 9.15) [este cuerpo que se corrompe, apesta el ánima]. Para muchas cosas para que el alma se sienta hábil y deseosa, le es estorbo el cuerpo. A la manera que cuando caminamos en una bestia de mal paso, y nos lleva molidos, tropieza a menudo, cánsase, y a veces no la podemos menear, espántase de la sombra, échase al mejor tiempo; tal es ahora nuestro cuerpo. Ese fue el castigo y justo juicio de Dios, dice San Agustín, esta es la pena y la justicia que mandó hacer la Majestad de Dios nuestro Señor contra el hombre desobediente, que pues él no quiso obedecer a su Criador y Señor, que tampoco le obedezca a él su carne y su apetito, sino que sienta en sí una continua guerra y rebelión ${ }^{49}$

El lugar del cuerpo en la definición de la persona es problemática dentro de esta tradición occidental, sin embargo, la dicotomía entre dos tipos de sustancias que nos conforman muestran que esta es una relación necesaria y que se debe llegar a un entendimiento con nuestro cuerpo para poder lograr el fin. El cuerpo, en tanto materia, permite cumplir la condena y estar en este mundo aprendiendo que se debe obedecer, y entender que lo menos noble debe sujetarse a lo que es más noble, como el siervo a su señor. Aquí, el cuerpo es una metáfora de las relaciones sociales, los plebeyos son el "cuerpo" o parte material de un "cuerpo mayor" -sistema político- y por tal condición son inferiores y deben sujetarse a sus superiores o "nobles":

encarnó Dios, uniéndose à la naturaleza humana en el Vientre purísimo de una Doncella de catorce años, de este modo: por aquel tiempo envió Dios desde el Cielo al Arcángel San Gabriel, à anunciarle con aquellas palabras con que ahora le saludamos... que desde la eternidad era elegida para Madre de Dios humanado, y primer albergue del Redentor de los Onbres, \&c. y sin mas que dar su consentimiento, y humilde aceptación de la palabra Divina, formó Dios instantáneamente de su purísima Sangre un Cuerpo de Onbre sin aquellas preparaciones, maturaciones, y progreso, que diuturnan la perfecta formación de nuestros Cuerpos: en un instante fue configurado aquel, y perfectamente organizado, en el mismo fue criada un Alma, y unida à aquel Cuerpo: y a este cuerpo vivo, ò à esta naturaleza de Onbre cumplida se unió en el mismo instante la segunda

49 Alonso Rodríguez, S.J., [47], 614. 
Persona de la Santísima Trinidad, quedando allí dos naturalezas, y una persona permaneciendo para siempre en la misma realidad de una persona sola las dos naturalezas distintas, divina, y humana.

"En nosotros mismos tenemos delineada la figura, con que puede entenderse en algún modo este Mysterio. Nuestra alma y nuestro cuerpo son dos naturalezas distintas, y muy distantes: la alma pudo aver sido un supuesto, como lo es cada uno de los espíritus Angélicos, sin consorcio de cosa material, y el cuerpo otro distinto, como lo son todos los Cuerpos, que carecen de espíritu, ò alma racional; y no lo fueron, porque Dios no echó à cada uno al Mundo solo con propia suposición, ò ejercicio separado del otro, de suerte que nuestra alma, y nuestro cuerpo no son dos personas, porque no andan obrando separados, ò porque están acompañados, obrando juntos con representación de una cosa completa, aunque ellas sean dos, y de clases material, y espiritual..."

La unión de estas dos naturalezas, llaman los teólogos unión hipostática, esto es, "que hace personalidad de entrambas naturalezas". Estamos revestidos de la Personalidad del Verbo. Lo más noble de nuestra persona es la alma o racionalidad, lo más noble, por eso se llama persona, si se tomara solo el cuerpo se llamara "supuesto":

"Esta voz es común à toda cosa, que tiene operaciones propias; y la de Persona distingue en ellas à las racionales, y espirituales ${ }^{50}$.

En ambos casos, el cuerpo es considerado parte de la naturaleza humana aunque incomoda y obstaculiza tanto la racionalidad como la espiritualidad, de este modo, solo las disciplinas, normas y reglas permitirán lograr su transformación en camino o medio para la salvación, es decir, su control, domesticación y subordinación a la parte noble de la naturaleza humana. Ahora podemos entender lo relevante de la discusión sobre la necesidad de la mortificación del cuerpo, así como lo que se entiende por ella. El debate sobre este punto, dentro de la Compañía de Jesús, es muy ilustrativo y especialmente interesante en tanto orden religiosa de la contrarreforma. La tradición jesuita no desterró las penitencias externas, pero la "modernidad" de la orden se advierte cuando previene que ellas deben quitar lo conveniente, y cuanto más mejor, por ejemplo en el comer o el dormir, pero que "corrompa el subieto ni se siga enfermedad notable". Lo mismo se recomienda para el castigo de la carne "lo que parece más cómodo y más seguro de la penitencia, es que el dolor sea sensible en las carnes y que no entre dentro de los huesos, de manera que dé dolor y no enfermedad; por lo qual paresce [sic] que es más conveniente lastimarse con cuerdas delgadas, que dan dolor de fuera, que no de otra manera que cause dentro enfermedad que sea notable" 51.

50 Sebastián Díaz de la Sagrada Orden de Predicadores, Noticia General De Las Cosas Del Mundo Por El Orden De Su Colocación. Para uso de la Casa de los Señores Marquezes de la Pica y para instrucción común de la Jubentud del Reyno de Chile. Primera Parte. Con Licencia en Lima: en la Imprenta Real, Calle de Concha, 1783. Parte primera de los cielos, y cosas, que contienen, primer artículo de los siete postreros, o de la umanidad, 75-78.

51 San Ignacio de Loyola, Ejercicios Espirituales en: Obras completas de San Ignacio de Loyola, Madrid, Biblioteca de Autores Cristianos, 1977. Primera semana, quinto ejercicio: meditación del infierno, adicciones para mejor hacer los ejercicios, adicción décima, 229. 
Los jesuitas son relevantes porque se hicieron cargo de la educación de América colonial ${ }^{52}$ poniendo en práctica el principio de la gravedad como dominio de sí mismos, una dignidad sin fisuras por medio de una pedagogía del cuerpo ${ }^{53}$. En esto coincidían con las órdenes reformadas que también insistían en el decoro y en la gravedad exterior, o los "ojos modestamente bajos". Pero solo los jesuitas, a decir de Marcel Bataillon, hicieron de ello una exigencia inflexible ${ }^{54}$. Por medio de textos dedicados a la educación de los niños, los jesuitas contribuyeron a la interiorización de la relación entre cuerpo e ideología social, entre prácticas públicas y privadas ${ }^{55}$.

Los castigos, mortificaciones y disciplinas del cuerpo permiten y pretenden "transmitir" el mensaje de que este es el lugar de lo "bajo". El cuerpo será el soporte de aplicación de las prácticas, porque los castigos son los que permiten instalar las nociones de justicia de occidente y, por tanto, también una particular noción de "cuerpo". Hay que preguntarse cuáles serían los puntos de conexión entre las lógicas sacrificiales de las sociedades americanas y las europeas, cuáles serían por tanto las correspondencias entre uno y otro sistema entre cuerpo, justicia y castigos. ¿Será la sangre, el golpe, la exposición pública, o el encierro lo que atormente más a los diferentes grupos? ¿Cómo se colonizó el cuerpo de los habitantes americanos desde la lógica del dolor del cuerpo? Las grietas dolorosas de la carne azotada nos deparan fructíferos caminos de comprensión y reconstrucción del proceso de colonización en América. En ningún caso es la reactualización de la leyenda negra de la conquista, sino que una propuesta sobre cómo y desde dónde entender los procesos de aculturación, transculturación y mestizaje que supone la constitución de una sociedad colonial, por lo tanto, de sus imaginarios aunque también respecto de los elementos comunes entre distintos grupos si asumimos que

52 Ver los trabajos de Pilar Gonzalbo Historia de la educación en la época colonial. La educación de los criollos y la vida urbana, México, El Colegio de México, 1990 (1999, reimpresión), 395 pp. y Pilar Gonzalbo Aizpuru, "La familia educadora en Nueva España: un espacio para las contradicciones", en: Pilar Gonzalbo A. (coord.), Familia y educación en Iberoamércica, El Colegio de México, Centro de Estudios Históricos, México, 1999, 43-55, La educación popular de los jesuitas, México, Universidad Iberoamericana-Departamento de Historia, 1898, 247 pp.

53 Alejandra Araya, "La pedagogía del cuerpo en la educación Novo-Hispana": Julio Retamal Ávila (coord.), Estudios Coloniales II, Editorial Biblioteca Americana/Universidad Andrés Bello, Santiago, 2002, 115-157.

54 Marcel Bataillon, "De Erasmo a la Compañía de Jesús. Protesta e integración en la Reforma Católica del siglo XVI", en Marcel Bataillon, Erasmo y el erasmismo, Crítica, Barcelona, 2000, 237 238.

55 En particular he trabajado con los siguientes: P. Gerónymo de Rosales de la Compañía de Jesús, Catón christiano, y catecismo de la doctrina christiana: para la educación, y buena crianza de los niños, y muy provechosa para personas de todos estados. Añadido con ejemplos, reimpreso en México en la imprenta nueva de la biblioteca mexicana, enfrente de San Agustín, año de 1761, 111 pp; Reglas de la buena crianza civil y christiana, utilísimas para todos, y singularmente para los que cuidan de la educación de los niños, quienes las deberán explicar, inspirándoles insensiblemente su práctica en todas ocurencias, Reimpresas en Puebla en la oficina de Don Pedro de la Rosa, año de 1802, 144 pp.; Pedro de Alonso Rodríguez, Catón español político christiano. Obra original para la enseñanza y buena educación de los niños, niñas y jóvenes. Acomodada al carácter, costumbres, leyes y religión de la nación española con advertencias político-morales a los padres y maestros, Con privilegio, Madrid, Imprenta de Aznar, 198 pp. 
el cuerpo es un gran símbolo natural. Las prácticas sobre el cuerpo y las relaciones con él constituyen procesos históricos profundos, puesto que sin dolor no podemos contar la historia de la dignidad de la persona humana. Paradójicamente, la propia cultura de la que somos parte en tanto intelectuales nos ha cegado frente a la historia que se cuenta desde el cuerpo afligido y adolorido.

Fecha de recepción: marzo de 2006

Fecha de aceptación: agosto de 2006 
